\title{
Liver
}

\section{Outcomes of parenchyma-preserving hepatectomy and right hepatectomy for solitary small colorectal liver metastasis: A LiverMetSurvey study}

\author{
Isamu Hosokawa, MD, ${ }^{\text {a,b }}$ Marc-Antoine Allard, MD, ${ }^{\text {a }}$ Darius F. Mirza, MD, ${ }^{\mathbf{c}}$ Gernot Kaiser, MD, ${ }^{\mathrm{d}}$ \\ Eduardo Barroso, MD, ${ }^{\mathrm{e}}$ Réal Lapointe, MD, ${ }^{\mathrm{f}}$ Christophe Laurent, MD, ${ }^{\mathrm{g}}$ Alessandro Ferrero, MD, ${ }^{\mathrm{h}}$ \\ Masaru Miyazaki, MD, ${ }^{\mathbf{b}, \mathbf{i}}$ and René Adam, MD, PhD, ${ }^{\mathbf{a}}$ Villejuif and Bordeaux, France, Chiba and Tokyo, \\ Japan, Birmingham, United Kingdom, Essen, Germany, Lisbon, Portugal, Montréal, QC, Canada, and Turin, \\ Italy
}

Background. Occasionally, right hepatectomy, rather than parenchyma-preserving hepatectomy, has been performed for solitary small colorectal liver metastasis. The relative oncologic benefits of parenchymapreserving hepatectomy and right hepatectomy are unclear. This study compared the outcomes of patients with solitary small colorectal liver metastasis in the right liver who underwent parenchyma-preserving hepatectomy and those who underwent right hepatectomy.

Methods. The study population consisted of a multicentric cohort of 21,072 patients operated for colorectal liver metastasis between 2000 and 2015 whose data were collected in the LiverMetSurvey registry. Patients with a pathologically confirmed solitary tumor of less than $30 \mathrm{~mm}$ in size in the right liver were included. The short- and long-term outcomes of patients who underwent parenchymapreserving hepatectomy were compared to those of patients who underwent right hepatectomy. Results. Of the 1,720 patients who were eligible for the study, 1,478 (86\%) underwent parenchymapreserving hepatectomy and 242 (14\%) underwent right hepatectomy. The parenchyma-preserving hepatectomy group was associated with lower rates of major complications $(3 \%$ vs $10 \% ; \mathrm{P}<.001)$ and 90-day mortality ( $1 \%$ vs $3 \% ; \mathrm{P}=.008)$. Liver recurrence occurred similarly in both groups $(20 \%$ vs $22 \%$; $\mathrm{P}=.39)$. The 5-year recurrence-free survival and overall survival rates were similar in both groups. However, in patients with liver-only recurrence, repeat hepatectomy was more frequently performed in the parenchymapreserving hepatectomy group than in the right hepatectomy group $(67 \%$ vs $31 \% ; \mathrm{P}<.001)$, and the overall 5-year survival rate was significantly higher in the parenchyma-preserving hepatectomy group than in the right hepatectomy group $(55 \%$ vs $23 \%$; $\mathrm{P}<.001)$.

Conclusion. Parenchyma-preserving hepatectomy should be considered the standard procedure for solitary small colorectal liver metastasis in the right liver when technically feasible. (Surgery 2017;162:223-32.)

\begin{abstract}
From the Centre Hépato-Biliaire, ${ }^{a}$ AP-HP Hôpital Paul Brousse, Villejuif, France; Department of General Surgery, ${ }^{b}$ Chiba University Graduate School of Medicine, Chiba, Japan; Department of HBP Surgery, ${ }^{c}$ Queen Elizabeth Hospital, Birmingham, United Kingdom; Department of General, Visceral and Transplantation Surgery, ${ }^{d}$ University Hospital of Essen, Essen, Germany; HBP and Transplantation Centre, ${ }^{e}$ Curry Cabral Hospital, Lisbon Central Hospitals Centre, Lisbon, Portugal; HPB Surgery and Liver Transplantation Unit, ${ }^{\prime}$ Centre Hospitalier de l'Université de Montréal, Hôpital Saint-Luc, Montréal, QC, Canada; Department of Hepatobiliary Surgery, ${ }^{g}$ CHU Bordeaux, Saint-André Hospital, Bordeaux, France; Department of General and Oncological Surgery, "Umberto I" Mauriziano Hospital, Turin, Italy; and Mita Hospital, ${ }^{i}$ International University of Health and Welfare, Tokyo, Japan
\end{abstract}

\footnotetext{
The authors declare that there are no conflicts of interest and no funding support. LiverMetSurvey is supported by an unrestricted grant from Sanofi-Aventis.

Accepted for publication February 17, 2017.

Reprint requests: René Adam, MD, PhD, Centre Hépato-Biliaire, AP-HP Hôpital Paul Brousse, 12 Avenue Paul Vaillant Couturier, Villejuif 94804, France. E-mail: rene.adam@aphp.fr.
}

0039-6060/\$ - see front matter

(C) 2017 Elsevier Inc. All rights reserved.

http://dx.doi.org/10.1016/j.surg.2017.02.012 
Surgical RESECTION offers the best chance for longterm survival in patients with colorectal liver metastases (CLMs). ${ }^{1} \quad$ Increasingly aggressive operations, the use of more effective perioperative chemotherapy, and improvements in imaging and patient selection have all contributed to improving the outcomes after resection for CLM. ${ }^{2}$ Securing sufficient surgical margins while preserving enough remnant liver parenchyma is the key for safe and effective surgical resection of CLM. ${ }^{3}$ Furthermore, it has been well established that repeat resection for recurrent CLM can offer prolonged survival. ${ }^{4-6}$

Occasionally, right hepatectomy (RH), rather than parenchyma-preserving hepatectomy $(\mathrm{PH})$, has been performed for solitary small CLM in the right liver to secure free surgical margins, reducing the risk of liver recurrence. However, to date, it is unclear whether $\mathrm{PH}$ increases the positive surgical margins or liver recurrence compared to RH. Furthermore, the oncologic benefit of $\mathrm{PH}$ over $\mathrm{RH}$ via its leaving enough liver parenchyma to enable repeat resection is also unclear.

Recently, Mise et al reported a single center's experience with $\mathrm{PH}$ and non-PH for solitary small CLMs. ${ }^{7}$ However, because the policy regarding this clinical situation is usually well designed for only one strategy in each center, a multicenter evaluation was necessary to include both types of strategies.

This study aimed to compare the surgical and long-term outcomes of patients with a solitary small CLM in the right liver who underwent PH and those who underwent RH using the data of a large, recent, multi-institutional, international database. We hypothesized that, in patients with a solitary small CLM in the right liver, $\mathrm{PH}$ would be associated with lower morbidity and mortality rates than RH, without increasing positive surgical margins or liver recurrence. Furthermore, we hypothesized that, in patients with liver recurrence, $\mathrm{PH}$ would be associated with better survival than RH because preserved liver parenchyma would allow more repeat hepatectomies than RH.

\section{METHODS}

Study population. The study population $(n=21,072)$ consisted of a multicentric cohort of patients operated for CLM between January 2000 and December 2015 and whose data were prospectively registered in the LiverMetSurvey international registry. The LiverMetSurvey (http://www. livermetsurvey.org) is a prospective international database that collects clinical and pathologic data of patients undergoing surgery for CLM. This register currently involves 302 centers across 59 countries. Data are entered using an online questionnaire, which includes demographic and pathologic variables of the primary tumor and of the liver metastases, as well as information concerning the type, duration, and effects of preoperative treatment; the surgical procedure; the timing, location, and treatment of recurrence; and the surgical and long-term outcomes. Data are regularly updated by each center. A data manager performs quality control of the data by automatic control of coherence and by sending personalized information to each contributing center twice a year.

Study design and definitions. Within the global cohort, patients who underwent surgical resection for solitary CLM of less than $30 \mathrm{~mm}$ in size in the right liver (segments 5, 6, 7,8) were eligible for this study. The number and size of CLMs were defined according to the pathologic diagnosis. The following patients were excluded from the study: (1) patients with initially unresectable disease; (2) patients who underwent preoperative portal vein embolization; (3) patients with macroscopically incomplete (R2) resection; and (4) patients showing evidence of concomitant extrahepatic disease.

$\mathrm{PH}$ was defined as nonanatomic partial resection or anatomic segmentectomy, bisegmentectomy, and sectionectomy. ${ }^{8}$ Major complications were defined as Clavien-Dindo grades III and IV morbidity. ${ }^{9}$ Synchronous CLMs were defined as CLMs detected at or before the diagnosis of the primary tumor. ${ }^{10}$

End points and statistical analysis. The primary end points in this study were postoperative major complications as defined above, 90-day mortality, recurrence-free survival (RFS), time to last unresectable recurrence, and overall survival (OS). RFS, time to last unresectable recurrence, and OS rates were calculated from the date of hepatectomy to first disease recurrence, last unresectable recurrence, or death, respectively. ${ }^{11}$ The secondary end points of the study were liver recurrence and repeat hepatectomy.

The $\mathrm{PH}$ group and $\mathrm{RH}$ group were compared using the $\chi^{2}$ or Fisher exact test for categorical data and the independent-samples $t$ test for continuous data. Survival curves were generated by the Kaplan-Meier method and compared by the log-rank test. To identify predictors of survival among the characteristics of initial hepatectomy in patients with liver-only recurrence, univariable and multivariable analyses were performed using the log-rank test and the Cox proportional hazard model, respectively. A multivariable risk model of 
Table I. Comparisons of the PH and RH groups in the overall cohort

\begin{tabular}{|c|c|c|c|c|c|}
\hline \multirow[b]{2}{*}{ Variable } & \multicolumn{2}{|c|}{$\begin{array}{r}\text { PH group } \\
(\mathrm{n}=1,478)\end{array}$} & \multicolumn{2}{|c|}{$\begin{array}{l}R H \text { group } \\
(\mathrm{n}=242)\end{array}$} & \multirow[b]{2}{*}{$\mathrm{P}$ value } \\
\hline & No. & $\%$ & No. & $\%$ & \\
\hline \multicolumn{6}{|l|}{ Patient } \\
\hline Age, y (mean $\pm \mathrm{SD})$ & \multicolumn{2}{|c|}{$64.1 \pm 11.0$} & \multicolumn{2}{|c|}{$64.0 \pm 10.0$} & .96 \\
\hline Sex: Male & 888 & 60 & 141 & 58 & .62 \\
\hline \multicolumn{6}{|l|}{ Primary tumor } \\
\hline Location: Rectum & 498 & 34 & 84 & 35 & .77 \\
\hline T stage: $3 / 4$ & 1,193 & 88 & 176 & 87 & .65 \\
\hline $\mathrm{N}$ positive & 846 & 62 & 126 & 61 & .76 \\
\hline \multicolumn{6}{|l|}{ CLM characteristics } \\
\hline Timing of diagnosis: Synchronous & 721 & 49 & 121 & 50 & .78 \\
\hline Tumor size, $\mathrm{mm}($ mean $\pm \mathrm{SD})$ & \multicolumn{2}{|c|}{$19.3 \pm 7.6$} & \multicolumn{2}{|c|}{$20.4 \pm 8.0$} & .04 \\
\hline CEA level, ng/mL (mean \pm SD) & \multicolumn{2}{|c|}{$65.7 \pm 303.0$} & \multicolumn{2}{|c|}{$159.7 \pm 1,347.6$} & .06 \\
\hline \multicolumn{6}{|l|}{ Perioperative management } \\
\hline Time period: $2008-2015$ & 1,008 & 68 & 162 & 67 & .70 \\
\hline Preoperative CT & 1,333 & 90 & 225 & 93 & .62 \\
\hline Preoperative MRI & 538 & 36 & 129 & 53 & $<.001$ \\
\hline Preoperative PET & 527 & 36 & 99 & 41 & .12 \\
\hline Preoperative chemotherapy & 455 & 32 & 84 & 36 & .23 \\
\hline Laparoscopic approach & 140 & 10 & 5 & 2 & $<.001$ \\
\hline Postoperative chemotherapy & 659 & 57 & 193 & 47 & .02 \\
\hline \multicolumn{6}{|l|}{ Surgical outcomes } \\
\hline Blood transfusion & 97 & 8 & 40 & 18 & $<.001$ \\
\hline Hospital stay, days (mean $\pm \mathrm{SD}$ ) & \multicolumn{2}{|c|}{$10.5 \pm 8.1$} & \multicolumn{2}{|c|}{$12.7 \pm 12.5$} & $<.001$ \\
\hline R0 resection & 1,238 & 94 & 215 & 95 & .64 \\
\hline Major complications & 49 & 3 & 24 & 10 & $<.001$ \\
\hline 90-day mortality & 11 & 1 & 7 & 3 & .008 \\
\hline \multicolumn{6}{|l|}{ Long-term outcomes } \\
\hline Recurrence & 529 & 36 & 84 & 35 & .77 \\
\hline Liver recurrence & 294 & 20 & 54 & 22 & .39 \\
\hline Liver-only recurrence & 172 & 12 & 35 & 14 & .20 \\
\hline Repeat hepatectomy & 187 & 13 & 18 & 7 & .02 \\
\hline
\end{tabular}

$S D$, Standard deviation; CT, computed tomography; MRI, magnetic resonance imaging; PET, positron emission tomography.

factors likely to predict survival of patients with liver-only recurrence included variables with $P \leq .10$ on univariable analyses. Factors with $P \leq .05$ were considered predictors of survival of patients with liver-only recurrence. The cut-off values of continuous variables for differentiation between the groups were determined based on receiver-operating characteristic curve analysis. All statistical analyses were performed using JMP version 12.0 (SAS Institute, Inc, Cary, NC).

\section{RESULTS}

Study population. Between January 2000 and December 2015, 21,072 patients underwent liver resection for CLM. Of them, 2,060 patients had a histologically solitary, $\leq 30-\mathrm{mm}$ tumor located in the right liver (Supplemental Fig 1). The following patients were excluded: 73 patients with initially unresectable disease; 50 patients with preoperative portal vein embolization; 76 with $\mathrm{R} 2$ resection; and 141 with concomitant extrahepatic disease. Of the 1,720 eligible patients, $1,478(86 \%)$ underwent $\mathrm{PH}$, and 242 (14\%) underwent RH.

Comparison of the $\mathbf{P H}$ group and the $\mathrm{RH}$ group in the overall cohort. Table I shows the patients' characteristics, surgical outcomes, and long-term outcomes of the patients who underwent $\mathrm{PH}$ $(n=1,478)$ or RH $(n=242)$.

The 3- and 5-year RFS rates were $51 \%$ and $43 \%$, respectively, in the $\mathrm{PH}$ group and $50 \%$ and $41 \%$, respectively, in the RH group $(P=.54$; Fig $1, A)$. The 3- and 5-year time to last unresectable recurrence rates were $64 \%$ and $52 \%$, respectively, in the $\mathrm{PH}$ group and $62 \%$ and $48 \%$, respectively, in the RH group $(P=.17$; Fig $1, B)$. After a mean follow-up of 41 months, the 3- and 5-year OS rates 

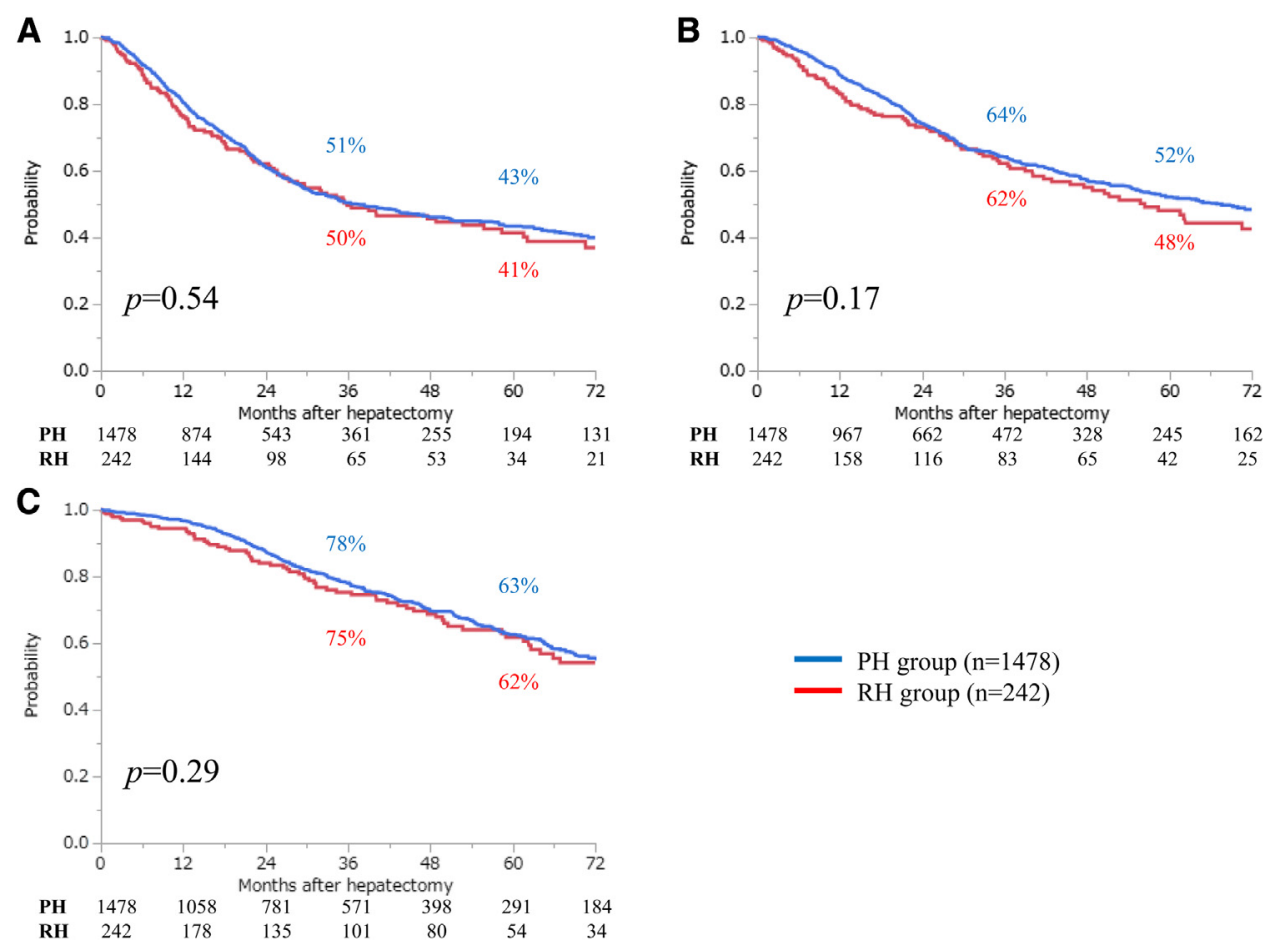

Fig 1. Kaplan-Meier analysis of $(A)$ recurrence-free survival (RFS), $(B)$ time to last unresectable recurrence, and $(C)$ overall survival (OS) of patients who underwent parenchyma-preserving hepatectomy (PH) and those who underwent right hepatectomy $(\mathrm{RH})$ for solitary small colorectal liver metastasis (CLM).

were $78 \%$ and $63 \%$, respectively, in the $\mathrm{PH}$ group and $75 \%$ and $62 \%$, respectively, in the RH group $(P=.29$; Fig $1, C)$.

Comparison of the $\mathbf{P H}$ group and the $\mathrm{RH}$ group in patients with liver-only recurrence. Table II shows the patients' characteristics, surgical outcomes, and long-term outcomes of patients who developed liver-only recurrence after $\mathrm{PH}$ $(n=172)$ or RH $(n=35)$.

In the $\mathrm{PH}$ group, $32 \%$ of the patients $(55 / 172)$ had bilateral liver disease recurrence. Of the remaining $68 \%(117 / 172)$ of patients with unilateral liver disease recurrence, $27 \%(46 / 172)$ had recurrence in the right liver (ipsilateral liver) only, whereas $41 \%(71 / 172)$ had recurrence in the left liver (contralateral liver) only (Supplemental Fig 2). Right-liver-only recurrence was less frequent than left-liver-only recurrence in patients with liver-only recurrence after $\mathrm{PH}(27 \%$ vs $41 \% ; P<.001)$. Repeat hepatectomy was performed more frequently in the $\mathrm{PH}$ group than in the $\mathrm{RH}$ group (67\% vs $31 \%$; $P<.001)$. In patients with liver-only recurrence after PH $(n=172), 110$ patients underwent nonanatomical resection as the initial hepatectomy. Of them, 80 patients $(80 / 110 ; 73 \%)$ underwent repeat hepatectomy. On the other hand, in patients with liver-only recurrence after $\mathrm{PH}(n=172)$, of 62 patients who underwent anatomic resection as the initial hepatectomy, 35 (35/62; 56\%) underwent repeat hepatectomy (Supplemental Fig 3). Repeat hepatectomy was performed more frequently after nonanatomic $\mathrm{PH}$ than after anatomic $\mathrm{PH}$ or $\mathrm{RH}$.

There was no difference in RFS between the 2 groups $(P=.72$; Fig $2, A)$. However, the 3 - and 5 -year time to last unresectable recurrence rates were $51 \%$ and $35 \%$, respectively, in the $\mathrm{PH}$ group and $25 \%$ and $9 \%$, respectively, in the $\mathrm{RH}$ group $(P=.005$; Fig 2, $B)$. Moreover, after a mean follow-up of 35 months, the 3- and 5-year OS rates were $78 \%$ and $55 \%$, respectively, in the $\mathrm{PH}$ group and $45 \%$ and $23 \%$, respectively, in the $\mathrm{RH}$ group $(P<.001$; Fig 2, $C)$.

Univariable and multivariable analyses of survival of patients with liver-only recurrence. Univariable analyses identified 5 characteristics at initial hepatectomy as being likely to influence OS in patients with liver-only recurrence $(P \leq .10$; Table III): sex, N stage of the primary tumor, tumor size of initial CLM, carcinoembryonic antigen (CEA) levels at hepatectomy, type of procedure, and length of hospital stay. On multivariable analysis, negative nodes of the primary tumor, CEA levels at hepatectomy $\leq 15 \mathrm{ng} / \mathrm{mL}$, and the $\mathrm{PH}$ procedure were identified as independent 
Table II. Comparison of the PH and RH groups in patients with liver-only recurrence

\begin{tabular}{|c|c|c|c|c|c|}
\hline \multirow[b]{2}{*}{ Variable } & \multicolumn{2}{|c|}{$\begin{array}{l}\text { PH group } \\
(\mathrm{n}=172)\end{array}$} & \multicolumn{2}{|c|}{$\begin{array}{l}R H \text { group } \\
(\mathrm{n}=35)\end{array}$} & \multirow[b]{2}{*}{$\mathrm{P}$ value } \\
\hline & No. & $\%$ & No. & $\%$ & \\
\hline \multicolumn{6}{|l|}{ Patient } \\
\hline Age, y $($ mean \pm SD $)$ & \multicolumn{2}{|c|}{$63.7 \pm 10.9$} & \multicolumn{2}{|c|}{$63.6 \pm 10.5$} & .99 \\
\hline Sex: Male & 104 & 60 & 20 & 57 & .71 \\
\hline \multicolumn{6}{|l|}{ Primary tumor } \\
\hline Location: Rectum & 61 & 35 & 14 & 42 & .55 \\
\hline T stage: $3 / 4$ & 140 & 89 & 24 & 80 & .22 \\
\hline $\mathrm{N}$ positive & 105 & 66 & 20 & 67 & 1.00 \\
\hline \multicolumn{6}{|l|}{ CLM characteristics } \\
\hline Timing of diagnosis: Synchronous & 103 & 60 & 13 & 37 & .02 \\
\hline Tumor size, mm (mean $\pm \mathrm{SD})$ & \multicolumn{2}{|c|}{$17.7 \pm 8.0$} & \multicolumn{2}{|c|}{$17.6 \pm 7.5$} & .97 \\
\hline CEA levels, $\mathrm{ng} / \mathrm{mL}($ mean $\pm \mathrm{SD})$ & \multicolumn{2}{|c|}{$41.3 \pm 127.4$} & \multicolumn{2}{|c|}{$58.0 \pm 110.2$} & .60 \\
\hline \multicolumn{6}{|l|}{ Perioperative management } \\
\hline Preoperative chemotherapy & 58 & 34 & 11 & 33 & 1.00 \\
\hline Laparoscopic approach & 13 & 8 & 0 & 0 & .13 \\
\hline Postoperative chemotherapy & 68 & 48 & 16 & 53 & .69 \\
\hline \multicolumn{6}{|l|}{ Surgical outcomes } \\
\hline Blood transfusion & 12 & 8 & 10 & 33 & .001 \\
\hline \multicolumn{6}{|l|}{ Hospital stay, days } \\
\hline Median (range) & \multicolumn{2}{|c|}{$8(2-131)$} & \multicolumn{2}{|c|}{$10(5-127)$} & \\
\hline Mean \pm SD & \multicolumn{2}{|c|}{$10.3 \pm 6.1$} & \multicolumn{2}{|c|}{$15.6 \pm 21.7$} & .008 \\
\hline R0 resection & 133 & 90 & 29 & 97 & .32 \\
\hline Major complications & 6 & 3 & 2 & 6 & .63 \\
\hline \multicolumn{6}{|l|}{ Recurrence characteristics } \\
\hline Time to recurrence: $<12$ months & 88 & 51 & 13 & 65 & .34 \\
\hline Tumor number $($ mean $\pm \mathrm{SD})$ & \multicolumn{2}{|c|}{$2.4 \pm 2.9$} & \multicolumn{2}{|c|}{$1.4 \pm 0.8$} & .16 \\
\hline Maximum tumor size, $\mathrm{mm}($ mean $\pm \mathrm{SD})$ & \multicolumn{2}{|c|}{$27.7 \pm 23.2$} & \multicolumn{2}{|c|}{$26.0 \pm 14.2$} & .78 \\
\hline Tumor distribution: Bilateral liver & 55 & 32 & 0 & 0 & \\
\hline CEA level, ng/mL (mean \pm SD) & \multicolumn{2}{|c|}{$175.0 \pm 621.9$} & \multicolumn{2}{|c|}{$96.4 \pm 126.7$} & .72 \\
\hline Repeat hepatectomy & 115 & 67 & 11 & 31 & $<.001$ \\
\hline
\end{tabular}

$S D$, Standard deviation.

predictors of good prognosis in patients with liveronly recurrence.

\section{DISCUSSION}

The present study confirms that, in patients with a solitary small CLM in the right liver, $\mathrm{PH}$ is associated with lower postoperative major complication and 90-day mortality rates than RH. Additionally, the present study clearly demonstrates that, in patients with liver-only recurrence after resection for a solitary small CLM, PH is associated with a higher OS rate compared with $\mathrm{RH}$ by increasing repeat resection for recurrence. This is the first report to compare $\mathrm{PH}$ and $\mathrm{RH}$ for solitary small CLMs based on a large, recent, multiinstitutional international database.

Mise et al reported a single center's experience with $\mathrm{PH}$ and non-PH for solitary small CLMs over a 20-year period. ${ }^{7}$ Use of the $\mathrm{PH}$ procedure had increased markedly at the MD Anderson Cancer Center over the study period. Furthermore, 3 different procedures, including right hepatectomy, left hepatectomy, and even left lateral sectionectomy, were performed as non-PH procedures. Therefore, it could be argued that the change in the surgical policy with time at a single center and the use of different procedures in the nonPH group might distort the results. Thus, a multiinstitutional study was conducted to compare $\mathrm{PH}$ and RH for a specific and strictly comparable clinical condition: solitary small CLMs in the right liver.

One of the potential disadvantages of $\mathrm{PH}$ compared to RH relates to the higher probability of positive surgical margins affecting the prognosis. ${ }^{12,13}$ However, in the current study, positive resection margin rates were similar between the $\mathrm{PH}$ group and the $\mathrm{RH}$ group. At present, margin width is considered not significantly related to 

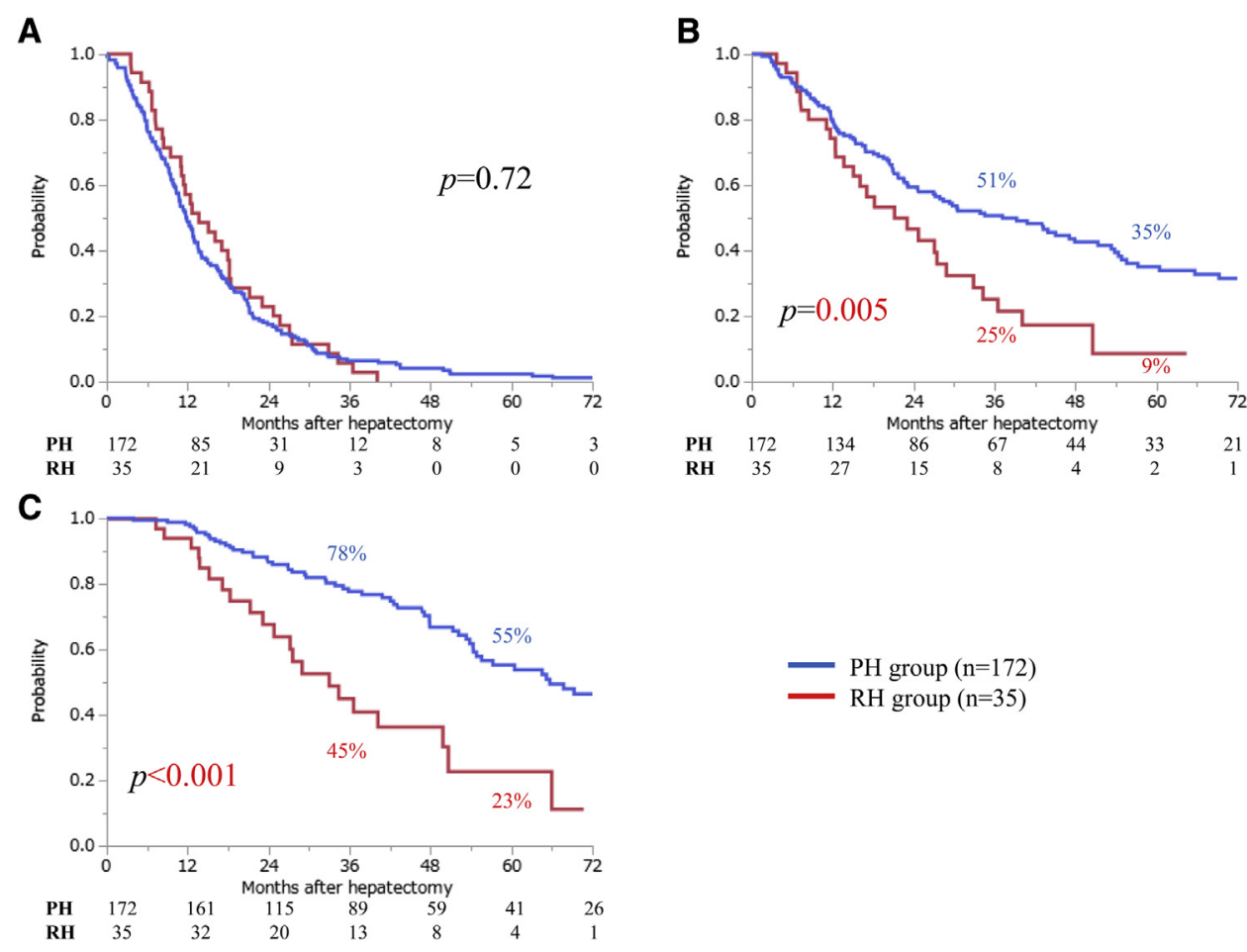

Figure 2. Kaplan-Meier analysis of $(A)$ recurrence-free survival (RFS), $(B)$ time to last unresectable recurrence, and $(C)$ overall survival (OS) of patients with liver-only recurrence who underwent parenchyma-preserving hepatectomy (PH) and those who underwent right hepatectomy (RH) for a solitary small colorectal liver metastasis (CLM).

survival after resection for CLM, ${ }^{14}$ and a $1-\mathrm{mm}$ surgical margin could be curative. ${ }^{15}$ More recently, it has been reported that even $\mathrm{R} 1$ resection, when $\mathrm{R} 0$ resection is not possible, might be acceptable in selected patients. ${ }^{16-18}$ Meanwhile, the current study showed that the $\mathrm{PH}$ procedure, rather than margin status, was an independent prognostic factor in patients with liver-only recurrence. These findings indicate that preserving liver parenchyma has, in practice, more impact on survival than margin width or margin status in patients with a solitary small CLM. Therefore, RH should not be performed for a solitary small CLM only because of a predicted close resection margin.

RH could be considered to decrease the risk of liver recurrence compared to $\mathrm{PH}$, due to wide removal of the at-risk liver parenchyma in which liver metastases could seed. ${ }^{7}$ However, the liver recurrence rate was similar between the 2 groups in this study. Furthermore, PH did not increase ipsilateral liver recurrence, as previously reported. ${ }^{19}$ These comparable liver recurrence rates after $\mathrm{PH}$ and after $\mathrm{RH}$ may be attributed to the induction of proliferation of micrometastases, as well as liver regeneration, by upregulating the expression of cytokines and growth factors after a major hepatectomy. ${ }^{20,21}$ Thus, despite the benefit of $\mathrm{RH}$ in removing the liver parenchyma at high risk of future liver metastases, regenerative growth factors after RH may induce liver parenchymal regeneration and tumor recurrence at the same time. Therefore, $\mathrm{RH}$ is not necessary or is useless in preventing liver recurrence after resection for a solitary small CLM.

Some patients may even benefit from repeat hepatectomy in the face of liver recurrence; thus, the preservation of liver parenchyma at the time of initial hepatectomy is potentially valuable. ${ }^{22}$ Theoretically, patients undergoing $\mathrm{PH}$, with the resultant preservation of the parenchyma, are more likely to have sufficient functional hepatic volume to allow for aggressive repeat resections when curative resection is possible. However, the relationships between the remnant liver volume after resection for CLM and salvageability for liver recurrence have not been clearly demonstrated. Thus, a subanalysis of patients with liver-only recurrence after resection for a solitary small CLM was conducted. In the present study, although there were no differences in the incidence and characteristics of recurrent CLM between the 2 groups, repeat hepatectomy could be performed more frequently after $\mathrm{PH}$ than after $\mathrm{RH}$, and, in addition, time to last unresectable 
Volume 162, Number 2

Table III. Univariable and multivariable analyses of survival of patients with liver-only recurrence

\begin{tabular}{|c|c|c|c|c|c|c|}
\hline Variable & $\mathrm{n}$ & $5-y$ OS (\%) & Univariable $\mathrm{P}$ & Multivariable $\mathrm{P}$ & $R R$ & $95 \% C I$ \\
\hline \multicolumn{7}{|l|}{ Patient } \\
\hline \multicolumn{7}{|l|}{ Age, y } \\
\hline$\leq 65$ & 115 & 49 & .69 & & & \\
\hline$>65$ & 92 & 51 & & & & \\
\hline \multicolumn{7}{|l|}{ Sex } \\
\hline Male & 124 & 59 & .02 & .07 & 1.77 & $0.96-3.27$ \\
\hline Female & 83 & 37 & & & & \\
\hline \multicolumn{7}{|l|}{ Primary tumor } \\
\hline \multicolumn{7}{|l|}{ Location } \\
\hline Rectum & 75 & 51 & .88 & & & \\
\hline Colon & 130 & 49 & & & & \\
\hline \multicolumn{7}{|l|}{ T stage } \\
\hline $3 / 4$ & 164 & 50 & .91 & & & \\
\hline $1 / 2$ & 23 & 47 & & & & \\
\hline \multicolumn{7}{|l|}{$\mathrm{N}$ stage } \\
\hline $1 / 2$ & 125 & 42 & .02 & .04 & 0.47 & $0.23-0.95$ \\
\hline 0 & 65 & 64 & & & & \\
\hline \multicolumn{7}{|l|}{ CLM characteristics } \\
\hline \multicolumn{7}{|c|}{ Timing of diagnosis } \\
\hline Synchronous & 116 & 49 & .71 & & & \\
\hline Metachronous & 90 & 52 & & & & \\
\hline \multicolumn{7}{|l|}{ Tumor size, mm } \\
\hline$\leq 20$ & 136 & 54 & 11 & & & \\
\hline$>20$ & 71 & 42 & & & & \\
\hline \multicolumn{7}{|c|}{ CEA levels, $\mathrm{ng} / \mathrm{mL}$} \\
\hline$\leq 15$ & 76 & 57 & .01 & .05 & 1.85 & $1.01-3.37$ \\
\hline$>15$ & 51 & 36 & & & & \\
\hline \multicolumn{7}{|c|}{ Hepatectomy characteristics } \\
\hline \multicolumn{7}{|c|}{ Preoperative chemotherapy } \\
\hline+ & 69 & 45 & .96 & & & \\
\hline- & 133 & 54 & & & & \\
\hline \multicolumn{7}{|l|}{ Type of approach } \\
\hline Laparoscopic & 13 & 0 & .12 & & & \\
\hline Open & 192 & 49 & & & & \\
\hline \multicolumn{7}{|l|}{ Type of procedure } \\
\hline $\mathrm{PH}$ & 172 & 55 & $<.001$ & .001 & 3.70 & $1.77-7.72$ \\
\hline RH & 35 & 23 & & & & \\
\hline \multicolumn{7}{|l|}{ Blood transfusion } \\
\hline+ & 22 & 44 & .24 & & & \\
\hline- & 155 & 54 & & & & \\
\hline \multicolumn{7}{|l|}{ Hospital stay, days } \\
\hline$\leq 14$ & 163 & 53 & .004 & .10 & 1.82 & $0.89-3.72$ \\
\hline$>14$ & 33 & 37 & & & & \\
\hline \multicolumn{7}{|l|}{ Margin status } \\
\hline R0 & 162 & 53 & .99 & & & \\
\hline R1 & 16 & 43 & & & & \\
\hline \multicolumn{7}{|c|}{ Major complications } \\
\hline+ & 8 & 56 & .14 & & & \\
\hline- & 199 & 50 & & & & \\
\hline Postoperative che & erapy & & & & & \\
\hline+ & 84 & 49 & .79 & & & \\
\hline- & 89 & 57 & & & & \\
\hline
\end{tabular}

$R R$, Risk ratio; $C I$, confidence interval. 
Table IV. The number of patients with solitary CLM according to tumor size in the LiverMetSurvey

\begin{tabular}{llcccc}
\hline & \multicolumn{2}{c}{$\begin{array}{c}\text { PH group } \\
(\mathrm{n}=1,883)\end{array}$} & & \multicolumn{2}{c}{$\begin{array}{c}\text { RH group } \\
(\mathrm{n}=368)\end{array}$} \\
\cline { 2 - 5 } & No. & $\%$ & No. & $\%$ & P value \\
\hline Tumor size $(\mathrm{mm})$ & & & & & $<.001$ \\
$\leq 20$ & 861 & 46 & 126 & 34 & .64 \\
$21-30$ & 617 & 33 & 116 & 32 & $<.001$ \\
$31-40$ & 405 & 22 & 126 & 34 & \\
\hline
\end{tabular}

recurrence was significantly longer after $\mathrm{PH}$ than after RH. On multivariable analysis, $\mathrm{PH}$ as the initial hepatectomy procedure was an independent prognostic factor in patients with liver-only recurrence. These findings indicate that the remnant liver volume after initial hepatectomy might correlate proportionally with salvageability for liver recurrence and survival of patients with CLM. This might be supported by the fact that repeat hepatectomy was performed more frequently after nonanatomic $\mathrm{PH}$ than after anatomic $\mathrm{PH}$ or $\mathrm{RH}$ in patients with liver-only recurrence. Therefore, it could be considered that, in patients with a solitary small CLM in the right liver, $\mathrm{PH}$ increases the chance of performing repeat resection for liver recurrence and, if so, leads to prolonged survival compared to RH.

The pathologic number and size of CLMs were used for selecting patients eligible for this study. Because techniques and quality of imaging studies might differ greatly in centers across the world, we decided to base our analysis on pathologic diagnosis, which seems more reproducible.

Tumor size is one of the most important factors in selecting PH or RH. An analysis of the number of patients with solitary CLM who underwent $\mathrm{PH}$ or $\mathrm{RH}$ according to tumor size ( $\leq 20 \mathrm{~mm}, 21-30 \mathrm{~mm}, 31-40 \mathrm{~mm}$ ) in the LiverMetSurvey showed that, for CLM of 31-40 mm in size, $\mathrm{PH}$ was performed less frequently than $\mathrm{RH}$ $(P<.001$; Table IV $)$. Therefore, the study was restricted only to patients with a solitary CLM of $<30 \mathrm{~mm}$ in size to exclude cases for which RH was inevitable to remove a large tumor.

It has been reported that the laparoscopic approach yields short- and long-term outcomes similar to those for the open approach for CLM. $^{23,24}$ Therefore, although the laparoscopic approach was more frequently performed in the $\mathrm{PH}$ group than in the $\mathrm{RH}$ group, the 2 groups in this study remained comparable in terms of outcomes.
In the overall cohort, long-term outcomes were similar between the PH group and the RH group. Because CLM represents a systemic disease, the incidence of recurrence is as high as $75 \%$, even after curative resection. ${ }^{11}$ In the current study, despite selecting the patients with the most favorable tumor biology among the CLM patients (solitary, $\leq 30 \mathrm{~mm}$ in size), the overall recurrence rate was about $35 \%$ in both groups. For this reason, the long-term outcomes of the patients who underwent $\mathrm{PH}$ and $\mathrm{RH}$ might be similar in the overall cohort. However, the development of a first relapse after initial hepatectomy does not mean definitive surgical failure or noncurability because repeat resection for recurrent disease has been accepted as providing a survival benefit and another chance for cure. ${ }^{11}$ Therefore, it is meaningful that the subgroup analysis of the patients with liver-only recurrence showed that $\mathrm{PH}$ was associated with a higher overall survival rate than RH because preserved liver parenchyma allowed more repeat hepatectomies than RH.

Finally, an important issue to consider is the risk of the operative procedure. Obviously, $\mathrm{PH}$ has less morbidity and mortality risk than RH. This, in view of the absence of any benefit provided by $\mathrm{RH}$, clearly increases the risk-benefit ratio of $\mathrm{RH}$ compared to $\mathrm{PH}$.

This study has several limitations. The first limitation of this study is its retrospective nature and the long study period. Second, pathologic tumor size was smaller and postoperative chemotherapy was performed more frequently in the $\mathrm{PH}$ group than in the $\mathrm{RH}$ group. The propensity score method enables us to obtain 2 groups that are well balanced for prognostic factors. ${ }^{25,26}$ However, including posttreatment variables as factors to calculate propensity scores is not recommended. ${ }^{27}$ Therefore, applying propensity score methods to match the pathologic tumor size and postoperative chemotherapy between the 2 groups was not appropriate. Third, there were no data about 
vascular connection of the resected metastases in the LiverMetSurvey. Thus, it was not possible to clearly identify patients who underwent RH but would have been technically suitable candidates for $\mathrm{PH}$; however, the patients with initially unresectable disease due to vascular proximity were excluded from this study. Thus, the potential influence of this issue on the results was probably limited. Fourth is the study's multicentric nature, with a variability of policy between centers in selecting the operative procedure. However, a comparative study of 2 different procedures might be difficult to conduct at a single center due to changes of surgical philosophy over time. ${ }^{28}$ Therefore, the present approach still provides a useful means of evaluating treatment methods for solitary small CLMs more precisely than was possible with conventional, retrospective, single-center studies.

In conclusion, this recent, large, multiinstitutional study demonstrated that, in patients with a solitary small CLM in the right liver, $\mathrm{PH}$ was associated with lower major complication and 90-day mortality rates than RH, without increasing positive surgical margins or liver recurrence. In patients with liver-only recurrence, $\mathrm{PH}$ was associated with a higher OS rate than after RH because preserved liver parenchyma allowed more repeat hepatectomies than RH. Therefore, in patients with a solitary small CLM in the right liver, PH, rather than $\mathrm{RH}$, should be considered the standard procedure when technically feasible.

\section{SUPPLEMENTARY DATA}

Supplementary data related to this article can be found online at http://dx.doi.org/10.1016/j.surg.2017.02.012

\section{REFERENCES}

1. Adam R, de Gramont A, Figueras J, Guthrie A, Kokudo N, Kunstlinger F, et al. The oncosurgery approach to managing liver metastases from colorectal cancer: a multidisciplinary international consensus. Oncologist 2012;17:1225-39.

2. Choti MA, Sitzmann JV, Tiburi MF, Sumetchotimetha W, Rangsin R, Schulick RD, et al. Trends in long-term survival following liver resection for hepatic colorectal metastases. Ann Surg 2002;235:759-66.

3. Adams RB, Aloia TA, Loyer E, Pawlik TM, Taouli B, Vauthey JN, et al. Selection for hepatic resection of colorectal liver metastases: expert consensus statement. HPB 2013;15:91-103.

4. Adam R, Bismuth H, Castaing D, Waechter F, Navarro F, Abascal A, et al. Repeat hepatectomy for colorectal liver metastases. Ann Surg 1997;225:51-62.

5. Andreou A, Brouquet A, Abdalla EK, Aloia TA, Curley SA, Vauthey JN. Repeat hepatectomy for recurrent colorectal liver metastases is associated with a high survival rate. HPB 2011;13:774-82.
6. Butte JM, Gönen M, Allen PJ, Peter Kingham T, Sofocleous CT, DeMatteo RP, et al. Recurrence after partial hepatectomy for metastatic colorectal cancer: potentially curative role of salvage repeat resection. Ann Surg Oncol 2015;22:2761-71.

7. Mise Y, Aloia TA, Brudvik KW, Schwarz L, Vauthey JN, Conrad C, et al. Parenchymal-sparing hepatectomy in colorectal liver metastasis improves salvageability and survival. Ann Surg 2015;263:146-52

8. Strasberg SM. Nomenclature of hepatic anatomy and resections: a review of the Brisbane 2000 system. J Hepatobiliary Pancreat Surg 2005;12:351-5.

9. Dindo D, Demartines N, Clavien PA. Classification of surgical complications: a new proposal with evaluation in a cohort of 6336 patients and results of a survey. Ann Surg 2004;240:205-13.

10. Adam R, de Gramont A, Figueras J, Kokudo N, Kunstlinger F, Loyer E, et al. Managing synchronous liver metastases from colorectal cancer: a multidisciplinary international consensus. Cancer Treat Rev 2015;41:729-41.

11. Oba M, Hasegawa K, Matsuyama Y, Shindoh J, Mise Y, Aoki T, et al. Discrepancy between recurrence-free survival and overall survival in patients with resectable colorectal liver metastases: a potential surrogate endpoint for time to surgical failure. Ann Surg Oncol 2014;21:1817-24.

12. Scheele J, Stang R, Altendorf-Hofmann A, Paul M. Resection of colorectal liver metastases. World J Surg 1995;19:59-71.

13. DeMatteo RP, Palese C, Jarnagin WR, Sun RL, Blumgart LH, Fong Y. Anatomic segmental hepatic resection is superior to wedge resection as an oncologic operation for colorectal liver metastases. J Gastrointest Surg 2000;4:178-84.

14. Kokudo N, Miki Y, Sugai S, Yanagisawa A, Kato Y, Sakamoto Y, et al. Genetic and histological assessment of surgical margins in resected liver metastases from colorectral carcinoma: minimum surgical margins for successful resection. Arch Surg 2002;137:833-40.

15. Hamady ZZ, Lodge JP, Welsh FK, Toogood GJ, White A, John T, et al. One-millimeter cancer-free margin is curative for colorectal liver metastases: a propensity score casematch approach. Ann Surg 2014;259:543-8.

16. Viganò L, Procopio F, Cimino MM, Donadon M, Gatti A, Costa $G$, et al. Is tumor detachment from vascular structures equivalent to R0 resection in surgery for colorectal liver metastases? an observational cohort. Ann Surg Oncol 2016;23:1352-60.

17. Torzilli G, Montorsi M, Donadon M, Palmisano A, Del Fabbro D, Gambetti A, et al. "Radical but conservative" is the main goal for ultrasonography-guided liver resection: prospective validation of this approach. J Am Coll Surg 2005;201:517-28.

18. Hosokawa I, Allard MA, Gelli M, Ciacio O, Vibert E, Cherqui D, et al. Long-term survival benefit and potential for cure after R1 resection for colorectal liver metastases. Ann Surg Oncol 2016;23:1897-905.

19. Kokudo N, Tada K, Seki M, Ohta H, Azekura K, Ueno M, et al. Anatomical major resection versus nonanatomical limited resection for liver metastases from colorectal carcinoma. Am J Surg 2001;181:153-9.

20. Tanaka K, Shimada H, Matsumoto C, Matsuo K, Takeda K, Nagano Y, et al. Impact of the degree of liver resection on survival for patients with multiple liver metastases from colorectal cancer. World J Surg 2008;32:2057-69.

21. von Heesen M, Schuld J, Sperling J, Grünhage F, Lammert F, Richter S, et al. Parenchyma-preserving hepatic 
resection for colorectal liver metastases. Langenbecks Arch Surg 2012;397:383-95.

22. Fisher SB, Kneuertz PJ, Dodson RM, Patel SH, Maithel SK, Sarmiento JM, et al. A comparison of right posterior sectorectomy with formal right hepatectomy: a dual-institution study. HPB 2013;15:753-62.

23. Beppu T, Wakabayashi G, Hasegawa K, Gotohda N, Mizuguchi T, Takahashi Y, et al. Long-term and perioperative outcomes of laparoscopic versus open liver resection for colorectal liver metastases with propensity score matching: a multi-institutional Japanese study. J Hepatobiliary Pancreat Sci 2015;22:711-20.

24. Allard MA, Sa Cunha A, Gayet B, Adam R, Goere D, Bachellier P, et al. Early and long-term oncological outcomes after laparoscopic resection for colorectal liver metastases: a propensity score-based analysis. Ann Surg 2015;262:794-802.
25. D'Agostino RB Jr. Prospensity score methods for bias reduction in the comparison of a treatment to a non-randomized control group. Stat Med 1998;17:2265-81.

26. Hosokawa I, Adam R, Allard MA, Pittau G, Vibert E, Cherqui D, et al. Outcomes of surgical shunts and transjugular intrahepatic portasystemic stent shunts for complicated portal hypertension. Br J Surg 2017;104:443-51.

27. Austin PC. An introduction to propensity score methods for reducing the effect of confounding in observational studies. Multivariate Behav Res 2011;46:399-424.

28. Gold JS, Are C, Kornprat P, Jarnagin WR, Gönen M, Fong Y, et al. Increased use of parenchymal-sparing surgery for bilateral liver metastases from colorectal cancer is associated with improved mortality without change in oncologic outcome: trends in treatment over time in 440 patients. Ann Surg 2008;247:109-17. 